\title{
What makes a market transaction morally repugnant?
}

\author{
Christina Leuker \\ Robert Koch-Institute, Max Planck Institute for Human Development \\ Lasare Samartzidis, \& Ralph Hertwig \\ Max Planck Institute for Human Development
}

February 19, 2021

Word count: 8612

\begin{abstract}
Many people find it morally impermissible to put kidneys, jury duty exemptions, or permits for having children on the free market. All of these are examples of repugnant transactions - market transactions that third parties want to prevent. In two studies $(N=1,554)$, using respondents' judgements of 51 different market transactions across 21 characteristics, we show that repugnance can be decomposed into five higher-order dimensions: moral outrage, need for regulation, incommensurability, exploitation, and unknown risk. Repugnance toward the 51 market transactions was highly consistent across two samples. Our results can help identify mismatches between public sentiments and current regulations (selling carbon emissions is currently legal but considered repugnant), anticipate responses to novel markets that have not been publicly scrutinized (often arising from technological advances, such as markets for "designer babies"), and help design less repugnant markets (e.g., by making the risks involved in a transaction known to sellers).
\end{abstract}

Keywords: repugnant transactions, moral judgments, market transactions, factor analysis, policy making

Data and analysis code can be retrieved via osf.io/efzsm. 
Dwarf tossing is a pub game in which contestants compete to throw people with dwarfism as far as possible. In many countries, human rights organisations have lobbied for dwarf tossing to be banned, arguing that it violates human dignity by objectifying people with dwarfism and that it represents a risk to those being tossed (CBC, 2012). Dwarf tossing is an instance of a repugnant transaction (Roth, 2007).

Repugnant transactions are market exchanges that third parties want to prevent (Roth, 2007) out of moral concerns. ${ }^{1}$ Repugnance is associated with a strong opposition to certain markets - stronger than an opposition to transactions that could be called "distasteful, inappropriate, unfair, undignified, or unprofessional" (Roth, 2007, p. 40). Repugnance has been observed in many domains, including prostitution, escort services, and the purchase and sale of human organs. Life insurance - the idea of setting a price on one's life, and then placing a bet on one's date of death - was initially considered repugnant (Zelizer, 1979; Roth, 2007). Some transactions have been classified as "taboo tradeoffs" (Fiske \& Tetlock, 1997; Tetlock, 2003) because people are unwilling or unable to compare the relative importance of secular values such as money, time, and convenience with values that have infinite or transcendent significance, such as love, honour, and justice. This may lead people to not only oppose particular transactions between third parties, but also refuse to take part in certain markets themselves.

Repugnance can be a "constraint on markets and how they are designed" (Roth, 2007, p. 40). For instance, many people find the thought of kidneys being sold on the free market repugnant (Roth, 2015). At the same time, in many countries patients may wait for years for a transplant because too few people are willing to donate kidneys. Monetary compensation may solve the problem: Within 11 years, Iran - the only country that allows kidneys to be sold on the free market - had virtually eliminated its waiting list for kidney transplants (Ghods \& Savaj, 2006; Hammond, 2018), though evidence is not unequivocal (Rouchi et al., 2014). Perhaps monetary incentives are stronger motivators than altruism (Lacetera, 2017). And yet, every country in the world but one bans the sale of kidneys on the free market. There is an immediate tension between "the efficiency enhancing effects of trades mediated by a monetary price and the moral opposition to the provision of these

\footnotetext{
${ }^{1}$ We added "moral concerns" to Roth's (2007) definition because people may want to prevent market transactions for economic reasons (e.g., competitors). The present research in part informs the definition of "repugnance" itself (see the Discussion section.)
} 
prices" (Lacetera, 2017, p. 14). Note, however, that involving money in a transaction may backfire for reasons other than moral opposition: People who register to donate an organ for altruistic reasons may be unwilling to register if money is involved, since financial incentives can undermine - or, "crowd out" - existing intrinsic motivations (Frey \& Oberholzer-Gee, 1997; Frey \& Jegen, 2001).

When and why do people want to restrict certain transactions? Feelings of repugnance vary across cultures and countries. For instance, prostitution is illegal in the US but legal in Germany, while surrogate motherhood is illegal in Germany but legal in the US. Slaughtering and selling cows is prohibited in most states in India, but in most other countries it is not given a second thought. Feelings of repugnance can also vary across time; for instance, alcohol, gambling, and life insurance were once considered repugnant but are now mostly accepted. Finally, feelings of repugnance can vary strongly across individuals even within the same country or culture: Some people find a kidney market perfectly acceptable while others do not (Roth, 2007), and people with dwarfism disagree on whether dwarf tossing is acceptable. In short, "repugnance is hard to predict" (Roth, 2007, p. 42).

Whereas prior qualitative research has compared and contrasted a variety of transactions and sought to explain what makes some transactions more repugnant than others (Roth, 2015, 2007; Satz, 2010; Sandel, 2013, 2012), extant quantitative research has, by and large, focused on research questions that concern specific transactions, such as how the acceptability of kidney donations changes as a function of the architecture of the particular transaction (e.g., the amount or form of payment). Apart from kidney donations (Decker et al., 2008; Elias et al., 2016; Niederle \& Roth, 2014; Querido et al., 2019) and organ donations more generally (Rodrigue et al., 2009), empirical research has also scrutinized clinical trials (Ambuehl et al., 2015; Leuker et al., 2020), blood donations (Goette \& Stutzer, 2020; Lee et al., 1999) and other transactions (see next section for details). However, quantitative research into the underlying psychological dimensions that shape feelings of repugnance is still scant. A clearer understanding of those dimensions would make it possible to determine similarities and dissimilarities between transactions by focusing on their "deep grammar" rather than their surface features. For instance, people may feel repugnance in response to any market transaction that involves largely unknown risks, such as selling organs or selling cocaine, even though on the surface they are two very different undertakings. Understanding how and why people respond to certain types of market transactions can also 
provide new entry points for policy intervention. For instance, if the main driver of public repugnance toward a transaction is exploitation of disadvantaged individuals, an effective policy response may have little in common with a policy for a transaction in which unknown risk is the main cause of repugnance. In one case the policy may be geared toward protecting vulnerable people, while in the other, the policy may focus on reducing and clearly communicating potential risks. In addition, policy makers who can identify the underlying dimensions of transactions that evoke strong opposition may be in a better position to anticipate responses to newly emerging markets and to recognize sensitive issues that require regulation. This is important, given that recent technological and scientific advances have often outpaced public scrutiny: Consider, for instance, algorithms that aim to predict an individual's sexual orientation (Wang \& Kosinski, 2018) or life expectancy (Briseño, 2018); insects processed for human consumption (Premalatha et al., 2011); tests for trisomies 21, 18, or 13 in fetuses (Quezada et al., 2015); gender selection and "designer babies" (Ball, 2018; Hercher, 2018); or the purchase and sale of autonomic weapons (Rahwan et al., 2019).

Here, we study the extent to which repugnance is quantifiable and predictable across 51 diverse transactions that are or have been considered repugnant. Respondents initially judged these transactions on 25 characteristics identified in the literature. Using these judgments, we applied a psychometric approach previously used by Slovic (1987) to understand how people think about, and respond to, a variety of risks, including handguns, fossil fuels, and vaccines. In Slovic's study, participants judged a number of risky activities and commodities on a range of characteristics that were then statistically combined into higher-order dimensions using a factor analysis. Those, in turn, were predictive of people's attitudes toward regulation of the risks. Following this approach, we also aim to identify the underlying dimensions crucial in people's judgments of repugnant transactions - the deep grammar of repugnant transactions. We do so in two independent studies $(N=1,554)$. In Study 1 , we had no prior expectations on the number of relevant higher-order dimensions that would emerge, and thus ran an exploratory factor analysis. In Study 2, we preregistered the expected number of factors based on the results obtained in Study 1. Before we describe the studies in detail, we provide a brief summary of our findings and turn to the characteristics that have been invoked in past research to explain the transactions' propensity to trigger feelings of repugnance.

The main findings and insights of our studies can be summarized as follows: First, we 
found that 25 characteristics previously identified in the study of repugnant transactions can be reduced to five distinct psychological dimensions: moral outrage, need for regulation, incommensurability, exploitation, and unknown risk. This classification means that these dimensions can be, for the time being, hypothesized to represent its deep grammar. Second, we were able to quantify the extent to which a total of 51 transactions are considered to be repugnant, and also to describe the notable heterogeneity in the extent to which these transactions trigger repugnant feelings, with some transactions consistently triggering strong collective disapproval (e.g., right to hunt endangered animals, bride price). Importantly, respondents' average judgments proved highly consistent across both studies. At the same time, there was substantial individual variability in how people assessed some of the moderately repugnant transactions (e.g., surrogate motherhood, horse meat in a restaurant, algorithms predicting life expectancy). This suggests that some types of transactions are "on ideological fringes," inducing approval in some individuals and opposition in others (Tetlock, 2003, p. 321). These transactions are a promising avenue for further investigations and public discourse: Why do people's opinions on these transactions vary, and can opinions change if characteristics of the transactions are altered? Third, we identified the extent to which each of the identified dimensions contributes to feelings of repugnance for each transaction, thereby offering hypotheses about the hot buttons that each transaction pushes. While many characteristics that make transactions repugnant have been articulated in extant literature, quantifying how different dimensions contribute to judged repugnance helps in determining which issues most urgently require public discourse. Fourth, we identified mismatches between judged repugnance of an transaction and its current legal status. For instance, respondents considered carbon emissions trading and selling permits to shoot rare animals highly repugnant, but both are legal in their countries. Such mismatches may be grounds for policy makers to take a closer look at certain transactions (also see Roth \& Wang, 2020). Note, however, that legalization does not necessarily need to reflect public sentiment-for instance, if the trade in question affects a minority population that, contrary to the majority, does not find it repugnant. Finally, we observed that the degree of moral outrage that a transaction prompts is a good predictor of the desire for regulation (comparable to "dread risk" in the case of desired regulation of risks; see Slovic, 1987), even though notable cases exist in which regulation is desired in the absence of moral outrage. In other words, the correlation between moral outrage and the need for regulation is imperfect. 
This can be accounted for theoretically because moral outrage can, in the absence of other reasons, be misplaced (Baier, 1960).

\section{Characteristics of Repugnant Transactions}

Previous research has identified characteristics that seem to trigger opposition to certain transactions. Here, we briefly review this literature. Our review reflects that research has focused on specific types of morally contested transactions (e.g., markets for body parts), even though these characteristics may apply across a range of transactions.

Financial compensation and price gouging. Money can make a transaction repugnant. Relatively few people are opposed to kidney donation, but many oppose selling kidneys to the highest bidder; in-kind benefits such as income tax credits to sellers are more accepted (Querido et al., 2019; Rodrigue et al., 2009). Money changing hands seems to be integral to repugnance in other domains as well: The practice of paying people to stand in line for lobbyists who wish to attend congressional hearings has been called into question (e.g., "linestanding.com"; see Sandel, 2013), and many people who have no problem with two parties entering a consensual intimate relationship may oppose the "economization" of intimate relationships found in escort services, prostitution, and pornography (Sandel, 2013). Sometimes, prices on transactions only meet with disapproval when they are too high, for instance selling basic necessities at higher prices after a natural disaster (price gouging; see Kahneman et al., 1986) or buying tickets to an event in order to sell them on at a higher price (ticket scalping; see Roth, 2007). Judging from these examples, transactions may be repugnant if they are perceived as exploiting the socioeconomically disadvantaged (Hill, 1994; Roth, 2007), highlight economic inequalities (Sandel, 2012), or objectify sellers by treating them as means to an end (Roth, 2007, also see Table 1).

Markets for body parts. The purchase and sale of body parts is probably one of the best-studied contested market transactions. Although free markets for organs could reduce or completely eliminate waiting lists for organ transplants (Ghods \& Savaj, 2006), there are concerns that organ markets can be manipulative and coercive. Research has explored whether these concerns can be addressed through how the market is designed (Lacetera, 2017; Niederle et al., 2008; Roth, 2015). For instance, kidney markets received more approval if the buyer was an institution (e.g., government) rather than an individual (Leider \& Roth, 2010). A similar logic may apply to clinical trials that typically offer significantly higher 
pay compared to other types of "unskilled" labour (Ambuehl, 2017; Roth, 2007; Wilkinson \& Moore, 1997). Thus, markets for body parts are often judged to be repugnant if they are seen as coercive (Ambuehl et al., 2015) or exploitative (also see previous section), or if they may expose participants to unknown risks (Ambuehl et al., 2015; Leuker et al., 2020).

Children and reproductive medicine. Buying a child from its mother is widely considered repugnant; however, in some countries it is legal and socially acceptable to pay surrogate mothers to carry a baby to whom they are genetically unrelated (Roth, 2007). Sperm donation $^{2}$ is legal in many countries-but the number of children, the amount of money that can be paid, and the eligibility of potential recipients are often restricted. Selling one's own child can be considered exploitative and coercive for poorer individuals. These examples also highlight that reproduction in general, including sperm donation may be considered sacred (Khalil \& Marciano, 2018), making them taboo trade-offs (Tetlock, 2003).

Sex, love, and friendship. Why are markets for sex (prostitution, pornography) or companionship (escort services) considered unacceptable by some? Many of the previously identified characteristics appear to play a role: Causing or inciting another person to become a prostitute for gain is an offence in the UK ("The Sexual Offences Act", 2003) because it is exploitative. Love and friendship may be considered "absolute and inviolable" (Tetlock, 2003), making prostitution and escort services taboo trade-offs. In addition, these transactions may also evoke concerns about effects they can have outside the transactions themselves. For example, sex markets may impact the communities in which they are found (Roth, 2007), and affected communities may intimidate and harass sex workers (Sanders, 2004). On the other hand, completely prohibiting these transactions may lead to black markets (Roth, 2015).

Blasphemy. Blasphemy can lead to or reflect discrimination, hatred, or hostility between groups with different religious beliefs or worldviews (Roth, 2007). Some consider Kanye West's album "Yeezus," in which he refers to himself as Jesus, to be blasphemous. At the same time, protected values such as freedom of speech preclude prohibiting all potentially blasphemous texts or art (indeed, the album Yeezus is not illegal). A crucial characteristic here may be the extent to which the transaction is harmful to society (Satz, 2010).

\footnotetext{
${ }^{2}$ Although payment is usually involved, this is the standard term.
} 
Drugs and addiction. One concern surrounding the purchase and sale of substances like alcohol, marijuana, or cocaine on the free market is their addictive nature (Roth, 2007). The same concern can be raised for gambling; governmental regulators often strive to strike a balance between reaping the benefits of a tax source and protecting citizens who gamble. Prohibiting transactions such as gambling or selling alcohol can be troublesome because voluntary buyers and sellers may respond to prohibitive laws by creating black markets (Roth, 2015, 2007), which may lead buyers into even riskier situations.

Civil duties. Civil rights and duties are often considered incommensurable with money (Tetlock, 2003). Even the mere act of contemplating buying citizenship or buying one's way out of jury duty or into college (Sandel, 2013; Roth, 2007) can "disqualify [people from their] moral community" (Tetlock, 2003, p. 321). In addition, selling them may be considered harmful to society (Satz, 2010).

Merit. Most people would agree that some goods, such as doctorates or scholarships, should be allocated based on merit (Sandel, 2013; Roth, 2007). Selling them is harmful to society (Ezell \& Bear, 2005; Satz, 2010) and likely opposes people's values.

Environment. Trophy hunters can travel to the Arctic and obtain the right to shoot a walrus. In 2013 , a trip cost $\$ 5,000-\$ 6,000$ (Sandel, 2013). The community that sells some of the permits it receives from the government to trophy hunters generally finds the transaction - in which both the meat and the money stay in the community-acceptable, but many others find this transaction repugnant. It does not align with their values and typically produces high moral outrage (Chivers, 2002; Herskovitz, 2014). Some critics also consider tradeable emissions (i.e., one's right to pollute) repugnant (Roth, 2007), although this market initially encountered relatively little opposition (Schmalensee et al., 1998). These transactions may be characterized by harms imposed on society (Satz, 2010), a strong conflict with one's values (Elias et al., 2017), and feeling personally affected by the transaction (Roth, 2015).

\section{Study 1: Exploratory Factor Analysis}

\section{Participants}

A total of $N=854$ respondents completed a survey posted on Prolific Academic for a flat payment of $£ 2.10$ for an average of 21 minutes of their time (interquartile range $=$ 17-27 minutes) in December 2018. Inclusion criteria were being a UK resident (indicated 
nationality $=.97 \mathrm{UK}$; indicated residence $=.99 \mathrm{UK}$ ), fluency in English (self-assessed), and a minimum approval rating of $80 \%$ in earlier studies completed on the platform. The survey was approved by the Institutional Review Board of the Max Planck Institute for Human Development. We analyzed data from $N=799$ respondents who passed two simple attention checks (questions pertaining to the instructions on the same page). The final sample consisted of 493 females, 301 males, and 5 respondents who identified as "other"; the average age of the sample was 38 years old (range 18-75 years, $S D=12.5$; see Supplementary Material 1.1 for distributions). The sample size for both studies was determined before any data analysis. We report all measures (individual difference measures and analyses are reported in the Supplementary Material).

\section{Survey}

Transactions. We retrieved our examples of potentially repugnant transactions from several sources: articles directly discussing repugnance (Roth, 2007), closely related empirical articles (e.g., Ambuehl, 2017; Leider \& Roth, 2010; Elias et al., 2016), works in political philosophy (e.g., Sandel, 2013; Satz, 2010) and psychology (Kahneman et al., 1986). From this literature, we retrieved 48 transactions that have been classified as repugnant, unethical, or "a good that should not be for sale" (Satz, 2010) and added three transactions of own interest to the list, for a total of 51. Transactions were taken from a variety of domains, such as transactions involving body parts or bodily functions (e.g., organs, life insurance, surrogate motherhood), transactions that may corrupt social values (e.g., child labour, standing in line for others, citizenship) and transactions that may pose a risk to the seller (e.g., boxing, clinical trials, cocaine). Each transaction was summarized in a brief sentence indicating the seller, the buyer, and the good they sought to exchange. For instance, the transaction child labour was summarized as follows: "A child under the age of 16 ('seller') is paid to work full time for a company/person ('buyer')." The Supplementary Material (Section 2) contains a list of all transactions and their summaries. To keep the survey manageable, each respondent evaluated the degree of repugnance and 25 characteristics (see below) of a random subset of three transactions.

General repugnance measure. The first evaluation respondents made pertained to the overall repugnance of a transaction. The measure consisted of three questions that people responded to on a 7-point Likert scale with reference points: (1) "How morally 
permissible do you consider transacting [name of transaction]?" (Morally impermissible $\Leftrightarrow$ Morally permissible) [reverse coded]; (2) "To what extent should transacting [name of transaction] be forbidden?" (Never forbidden $\Leftrightarrow$ Always forbidden); and (3) "To what extent would transacting [name of transaction] be permissible if no money changed hands?" (Morally impermissible $\Leftrightarrow$ Morally permissible) [reverse coded]. These questions were constructed from the definition of repugnant transactions (Roth, 2007; Sandel, 2013) and slightly adapted from an earlier empirical study (Leuker et al., 2020). In general, the scale achieved high internal consistency (Cronbach's $\alpha=.84$ ). Therefore, in the analyses, we use a participant's mean judgments to all three questions as a dependent variable. Note that robustness checks using only the first question-To what extent is a given transaction morally permissible? - showed that this analytic decision did not systematically alter our conclusions. This can also be expected based on the high correlation between the three items.

Characteristics. We identified 25 characteristics that have been shown or suggested to be associated with repugnance (e.g., Roth, 2007; Lacetera, 2017; Elias et al., 2015; Ambuehl, 2017; Bruneau et al., 2017; Sandel, 2013, see Table 1). Respondents assessed transactions on these 25 characteristics on 7-point Likert scales with reference points. The question order was randomized across participants. 
Table 1

Characteristics Identified in Extant Literature on Repugnant Transactions, Closely Related Empirical Articles, and Work in Political Philosophy Characteristic

(1) Amount of money (Roth, 2007)

(2) No direct payments (Lacetera, 2017)

(3) Governmental involvement (Leider \& Roth, 2010)

(4) International (Roth, 2007)

(5) Undue influence (Ambuehl, 2017; Elias et al., 2015)

(6) Seller's risk (Leuker et al., 2020)

(7) Buyer's risk (own)

(8) Risk known to seller (Leuker et al., 2020)

(9) Understand consequence (Ambuehl \& Ockenfels, 2017)

(10) Exploitative (Hill, 1994; Roth 2007)

(11) Objectification (Roth, 2007)

(12) Dignity seller (Elias et al. 2016

(13) Personally affected (Roth, 2015)

(14) Conflict with values (Elias et al., 2016)

(15) Common (own)

(16) Experience as a seller (own)

(17) Experience as a buyer (own)

(18) Empathy buyer (Bruneau et al., 2017)

(19) Empathy seller (Bruneau et al. 2017)

(20) Disgust (Nussbaum, 2010)

(21) Sacredness of good (Khalil \& Marciano, 2018

(22) Harmful to society (Satz, 2010)

(23) Fairness (Elias et al., 2016; Kahneman et al., 1986)

(24) Inequalities (Sandel, 2012

(25) Black markets (Roth, 2015) Wording of question with labels in empirical studies

Domain in origi"How much money would be acceptable to change hands when transacting [TRANSACTION]?" (No money $\Leftrightarrow$ Any amount Kidneys, Clinical agreed upon) trials

extent would offering an incentive other than money (e.g., tax credit) be acceptable?" (Completely acceptable $\Leftrightarrow$ Kidneys Completely unacceptable)

"To what extent should the government or an institution act as an intermediary (the "buyer") in transacting [TRANSACTION] Kidneys (i.e., should a governmental agency/institution make a standard payment to the seller)?" (Anyone can sell to anyone $\Leftrightarrow$ Government/institution needed)

"To what extent should transacting [TRANSACTION] be restricted to the buyer's/seller's own country?" (Only own country Kidneys $\Leftrightarrow$ Worldwide)

"To what extent does the involvement of money have an undue influence on the seller's decision when transacting [TRANS- Clinical trials, OrACTION] ?" (No undue influence $\Leftrightarrow$ Strong undue influence) gans

"To what extent does transacting [TRANSACTION] pose a risk to the buyer?" (No risk at all $\Leftrightarrow$ High risk)

Clinical trials

"To what extent are the risks known to the seller?" (Completely known $\Leftrightarrow$ Completely unknown)

Clinical trials

"To what extent can the consequences of transacting [TRANSACTION] be fully understood by the seller?" (Fully understand- Human egg donaable $\Leftrightarrow$ Not understandable at all) tion

"Does transacting [TRANSACTION] leave some people, particularly the poor, open to exploitation?" (Not at all open to Various (e.g., prosexploitation $\Leftrightarrow$ Completely open to exploitation) $\quad$ titution)

"Does putting a price on [TRANSACTION] objectify it or those involved in the transaction?" (Does not objectify at all $\Leftrightarrow$ Organs Completely objectifies)

"How does transacting [TRANSACTION] affect the dignity of the seller?" (Promotes human dignity $\Leftrightarrow$ Violates human Kidneys dignity)

"If it were legal and common, how would transacting [TRANSACTION] affect you personally?" (Not affected at all $\Leftrightarrow$ Strongly Various affected)

"Is transacting [TRANSACTION] compatible with your values?" (Compatible $\Leftrightarrow$ Incompatible)

Human egg dona-

"Is transacting [TRANSACTION] common in your society?" (Very rare $\Leftrightarrow$ Very common)

tion

"Have you considered selling [TRANSACTION]?" (Never $\Leftrightarrow$ Often)

"Have you considered buying [TRANSACTION]?" (Never $\Leftrightarrow$ Often)

"To what extent can you relate to the buyer of [TRANSACTION]?" (Cannot relate at all to buyer $\Leftrightarrow$ Can fully relate to buyer) -

"To what extent can you relate to the seller of [TRANSACTION]?" (Cannot relate at all to seller $\Leftrightarrow$ Can fully relate to seller) -

"To what extent do you consider transacting [TRANSACTION] disgusting?" (Not at all disgusting $\Leftrightarrow$ Extremely disgusting) "Do you consider [TRANSACTION] to be sacred?" (Not at all sacred $\Leftrightarrow$ Highly sacred)

Various (e.g., Sex)

"To what extent is transacting [TRANSACTION] harmful to society?" (Not at all harmful $\Leftrightarrow$ Extremely harmful)

Various

"To what extent is transacting [TRANSACTION] advantageous for the seller or the buyer?" (Advantageous for seller $\Leftrightarrow$ Various Advantageous for buyer)

"To what extent does transacting [TRANSACTION] highlight economic inequalities (i.e., class-based privileges and disadvantages)?" (Not at all $\Leftrightarrow$ Very much) "If tran
likely) 
Throughout, we refer to each of these characteristics using their referents in Table 1 (first column, bold). Including the general repugnance measure, each participant made 84 judgments ( 28 per transaction $\times 3$ transactions).

Individual differences. At the end of the survey, we explored individual differences with brief scales and measures of interest including a personality scale (Soto \& John, 2017), a market attitudes scale (Goff \& Noblet, 2018), and a question about religiosity. The scales were always presented in the same order, but items within scales were randomized. The survey concluded with demographic questions (gender, age, education, income, country of origin, country of residence). As religion may in part determine the extent to which some goods are considered sacred, we also asked respondents to indicate the extent to which religion is an important aspect of their life (7-point Likert scale: Not at all important $\Leftrightarrow$ Very important). Analyses of individual differences in judgments of repugnance, complete scales, and evaluations of internal consistency (Cronbach's alpha) can be found in the Supplementary Material (Section 7). These analyses showed that respondents who consider some goods sacred, consider religion important, subscribe to deontological reasoning, or hold conservative political views were more likely to rate the transactions in our set to be more repugnant. Respondents who subscribed to utilitarian reasoning considered the transactions in our set overall less repugnant.

\section{Statistical Analyses}

Bayesian regression modeling. We relied on Bayesian estimation techniques (Kruschke, 2014) and applied Bayesian Generalized Linear Models using Stan in R for regression analyses with the brms package (Bürkner, 2017). Likert scale data-typically not normally distributed - was modelled with ordinal cumulative regression models (Bürkner \& Vuorre, 2018). We controlled for individual variation by adding a random "respondent" intercept in all models that used more than one observation per individual. We relied on leave-one-out crossvalidation (LOO) to identify best-fitting models (Bürkner, 2017). These analyses suggested that models controlling for individual variation (with respondent intercepts) yielded better fit (indicated by lower LOO values) than those that did not. We investigated the convergence of posteriors through visual inspection and the Gelman-Rubin statistic (Gelman \& Rubin, 1992). We used weakly informative default priors from the brms package Bürkner \& Vuorre (2018). 
In general, we report the mean of the posterior distribution of the parameter or statistic of interest and two-sided 95\% equal tail credible intervals (CI) around each value. Our focus is on estimating the effects of particular conditions and our analyses reflect this goal; in comparing the models and predictors, however, the crucial issue was whether the $\mathrm{CI}$ included 0 or not. If the interval around a given coefficient does not include 0 , there is a credible positive (negative) association between variables in a given regression model.

Factor analysis. To investigate whether the characteristics of repugnance can be reduced to a lower number of higher-order factors, we conducted an exploratory factor analysis (EFA) using the package psych in R (Revelle, 2018). Our methodical choices are based on recommendations from Costello \& Osborne (2005). We excluded two items for which skewness and kurtosis exceeded $|2|$ (experience as a seller and experience as a buyer) and one item with an inadequate amount of variance for a factor analysis (fear that black markets would emerge if transaction were illegal), leaving 22 items in the analysis. We allowed for respondents' evaluations of various properties to be correlated, and thus chose an oblique (oblimin) method to rotate extracted factors. In selecting our final model, we sought to identify a clean factor model that exhibits item loadings above 0.32 , none or few items with crossloadings between factors (Costello \& Osborne, 2005), a reasonable Tucker Lewis Index (a fit index in which a cutoff of .95 or greater indicates good model fit), and theoretically sensible factors. Further details and model code are provided on the Open Science Framework (osf.io/efzsm).

\section{Results}

\section{Repugnance by Transaction}

Figure 1 shows that mean judgments of repugnance across the 51 transactions were highly variable. The most permissible transactions included buying and selling alcohol $(M=1.58[1.26,1.95])$, medical marijuana $(M=1.75[1.40,2.14])$, and life insurance $(M=$ $1.74[1.40,2.12])$ - transactions that are also legal in the UK, albeit with restrictions. The most repugnant transaction was selling the right to hunt an endangered animal $(M=6.11$ $[5.90,6.24])$; other highly repugnant transactions included selling voting rights $(M=5.83$ $[5.55,6.03])$ and bride prices $(M=5.66[5.37,5.89])$. The Supplementary Material (Section 5.1) lists coefficients with Bayesian highest density intervals for all transactions, ordered from least to most repugnant. 


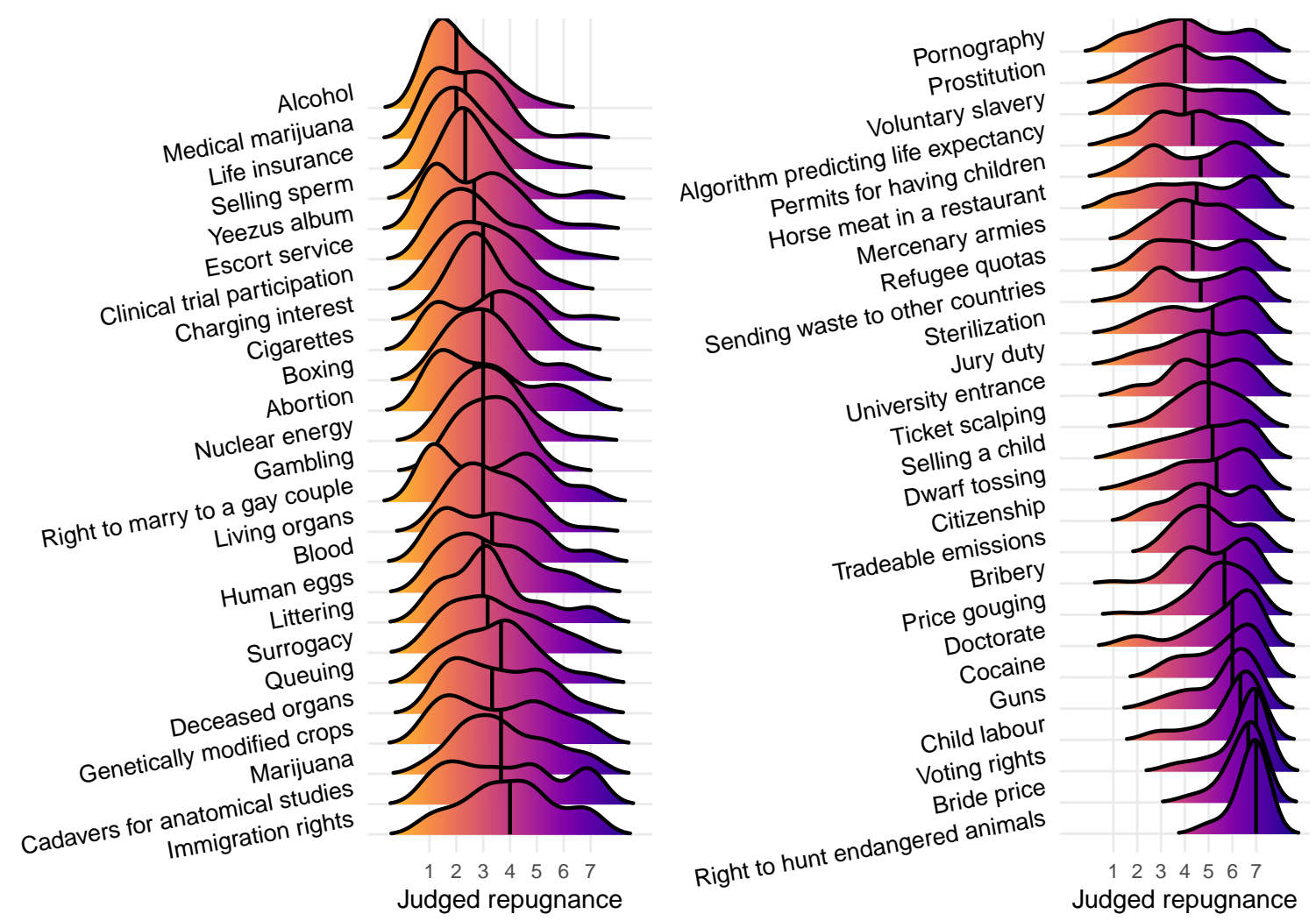

Figure 1. Judged repugnance across transactions (ordered from least to most repugnant transaction) in Study 1. Vertical lines represent median judgments across respondents.

\section{Dimensions (Exploratory Factor Analysis)}

Many of the characteristics of transactions assessed by our respondents are likely to be correlated across different transactions. For example, transactions that were judged "exploitative" may also have been judged "harmful to society" and transactions that were judged "common" may correlate with a respondent's "experience as a buyer." Such patterns of correlations can be investigated systematically with a factor analysis, revealing a condensed number of factors or dimensions ${ }^{3}$ along which (more or less) morally contested market transactions can be described.

We conducted an exploratory factor analysis with no prior hypotheses about the number and the nature of the factors to emerge. Table 2 shows the best-fitting solution of this analysis. The solution is a compromise of reasonable fit indices (e.g., a Tucker Lewis Index of 0.99 , where a cutoff of .95 or greater indicates good model fit), a limited amount

\footnotetext{
${ }^{3}$ We use the term factors when referring to the statistical analysis and dimensions when referring to the psychological interpretations of the factors identified in the analysis.
} 
Table 2

Six-Factor Model Solution

\begin{tabular}{|c|c|c|c|c|c|c|c|}
\hline \multirow{2}{*}{ Factor } & \multirow{2}{*}{ Characteristic } & \multicolumn{6}{|c|}{ Factor Loadings } \\
\hline & & (1) & (2) & (3) & (4) & (5) & (6) \\
\hline \multirow{8}{*}{ (1) Moral disgust } & No direct payments & 0.91 & & & & & \\
\hline & Disgust & 0.85 & & & & & \\
\hline & Empathy seller & -0.84 & & & & & \\
\hline & Empathy buyer & -0.84 & & & & & -0.30 \\
\hline & Conflict with values & 0.83 & & & & & \\
\hline & Harmful to society & 0.69 & & & & & \\
\hline & Dignity seller & 0.65 & 0.40 & & & & \\
\hline & Common & -0.46 & & -0.38 & -0.41 & & \\
\hline \multirow{4}{*}{ (2) Exploitation } & Exploitative & & 0.85 & & & & \\
\hline & Inequalities & & 0.81 & & & & \\
\hline & Undue influence & & 0.63 & & & & \\
\hline & Objectification & 0.38 & 0.46 & & 0.30 & & \\
\hline \multirow{2}{*}{ (3) Unknown risk } & Risk known to seller & & & 0.92 & & & \\
\hline & Understand conseq. & & & 0.92 & & & \\
\hline \multirow{3}{*}{ (4) Incommensurability } & Fairness & & & & 0.74 & & 0.37 \\
\hline & Sacredness of good & & & & 0.72 & & \\
\hline & Acceptance of money & -0.39 & & & -0.48 & & 0.35 \\
\hline \multirow{4}{*}{ (5) Need for regulation } & Gov. involvement & & & & & 0.81 & \\
\hline & Buyer's risk & & 0.36 & & & 0.57 & \\
\hline & International & & & & & -0.53 & \\
\hline & Personally affected & & & & & 0.46 & -0.36 \\
\hline (6) Seller's risk & Seller's risk & & 0.34 & & & & 0.73 \\
\hline Variance (proportion) & & 0.24 & 0.13 & 0.10 & 0.08 & 0.08 & 0.06 \\
\hline Variance (cumulative) & & 0.24 & 0.37 & 0.47 & 0.55 & 0.63 & 0.69 \\
\hline
\end{tabular}

Note. Only loadings above .3 are displayed; properties are ordered based on their loadings to the six factors. We allowed for respondents' evaluations of various properties to be correlated (oblimin method).

of crossloadings between factors, and avoiding factors with fewer than three items (though see factors 3 and 6$)$.

The factor analysis revealed six dimensions associated with repugnant transactions: moral disgust, exploitation, unknown risk, incommensurability, need for regulation, and seller's risk. Moral disgust arises when a person finds a transaction disgusting and strongly opposed to their values and has little empathy for anyone engaging in the transaction. Note that the item "No direct payments" also loaded on the factor moral disgust. This item probed the permissibility of a transaction if it offered incentives other than money (e.g., tax credit). This correlation likely arose because people opposed the transactions in our 
set just as strongly if the seller were to be offered incentives other than immediate monetary payment (e.g., tax credits). We removed this item in Study 2 since it is theoretically unrelated to moral disgust. Exploitation is judged to be higher the more a transaction objectifies the seller and the more coercive it is. Unknown risks may be a concern if the risks or consequences of a transaction are poorly understood. Incommensurability denotes that no amount of money is considered acceptable in a transaction (e.g., for brides), or that a good or service is considered sacred. Fairness also loaded on this factor but crossloaded with seller's risk. We suspected this was due to the reference points (advantageous to seller $\Leftrightarrow$ advantageous to buyer). We rephrased the "fairness" question and its reference points in Study 2, and do not interpret it further here. Next, some transactions may be characterized by a need for regulation; this indicates a call for governmental involvement and a restriction to the buyer's and seller's own country (as opposed to international trade). Interestingly, "buyer's risk" was also associated with this factor, potentially because respondents interpreted the question as the "buyer's risk" of being sanctioned. We tested this hypothesis in the second study. Lastly, seller's risk emerged as an own factor. As multiple items are needed to obtain a stable, reasonable factor structure, we do not interpret it further here. We rephrased this factor in Study 2.

\section{Conclusion}

The results of Study 1 suggest that repugnance toward a specific transaction can be quantified and possibly predicted. Study 1 identifies key dimensions that appear to make up the deep grammar of repugnant transactions. They can be used to map all market transactions in our set onto a factor space and compare them across these dimensions. Transactions that score high on all dimensions may be seen as most repugnant. We report these analyses, a more detailed discussion of the factors, and an analysis of individual differences in Study 2 , in which, importantly, we first replicated the proposed factor structure.

\section{Study 2: Replication and Extension of Study 1 Dimensions}

In Study 2, we sought to confirm and improve the proposed exploratory factor model from Study 1 in a new sample. Whereas Study 1 focused on UK citizens, anyone fluent in English (self-assessed) was eligible to participate in Study 2. Before collecting data, we preregistered the factor structure we expected to emerge (based on Study 1), the number of items 
and transactions, sample size, and exclusion criteria on aspredicted.org/blind.php? $x=y t 2 v ? k$.

\section{Participants}

A total of $N=855$ respondents completed our survey on Prolific Academic for a flat payment of $£ 2.10$ for an average of 25 minutes of their time (interquartile range $=$ 18-30 minutes) in July 2019. Inclusion criteria were fluency in English (self-assessed) and a minimum approval rating of $80 \%$ in earlier studies completed on the platform. Respondents who took part in Study 1 were excluded from taking part. The survey was approved by the Institutional Review Board of the Max Planck Institute for Human Development. We analyzed data from $N=755$ respondents who passed two simple attention checks (questions pertaining to the instructions on the same page). The final sample consisted of 392 females, 358 males, and 5 respondents who identified as "other"; the average age of the sample was 31 years old (range $18-76$ years $^{4}, S D=10.7$ ). Nationalities primarily included the UK (.32), Poland (.10), Portugal (.09) and a diverse set of other countries worldwide; a similar pattern emerged for respondents' current country of residence (see Supplementary Material Section 1.2 for distributions of main sample characteristics).

\section{Survey (Adapted)}

We administered the same survey as in Study 1, but with modifications to the questions about the properties of the transactions. Based on the exploratory factor analysis in Study 1, we predicted that five factors would emerge in a novel sample (we removed the question loading on factor 6): moral disgust, exploitation, unknown risk, incommensurability, and need for regulation. In order to reach a cleaner factor structure, we implemented three changes relative to Study 1. First, we changed the wording of some questions. For instance, the "fairness" question originally asked whether the transaction was more advantageous for the seller or the buyer with reference points (advantageous to seller $\Leftrightarrow$ advantageous to buyer) and loaded on multiple factors. The revised question only asked for the extent to which the transaction is advantageous to the buyer. Second, we removed two questions that did not produce enough variance (fear that black markets would emerge, experience as a seller), two that loaded on several factors and could not be uniquely assigned (common in own society, objectification of the seller) and a question that was conceptually unrelated to

\footnotetext{
${ }^{4}$ One person indicated being 16 years old, which is inconsistent with Prolific records and terms of use; it also did not match the age listed on their Prolific ID.
} 
factor 1 ("No direct payments"). Third, we added four new questions for factors that had a low number of properties loading on them $(2-3)$ in order to obtain a more robust factor structure (e.g., we added "How regulated should [name of transaction] be in your society?", completely regulated $\Leftrightarrow$ not regulated at all) and predicted this item to load on the factor need for regulation. Lastly, the property "seller's risk" emerged as an own factor in Study 1 but crossloaded with the factor need for regulation. We rephrased this question ("To what extent does the buyer of [name of transaction] risk being sanctioned by the state?", not at all $\Leftrightarrow$ very much) and predicted it to load on the factor need for regulation. In total, Study 2 respondents evaluated a random subset of three transactions regarding the degree of repugnance and 21 other properties (compared to 25 in Study 1). The complete list of questions is provided in the Supplementary Material (Section 6.2).

\section{Results}

\section{Repugnance by Transaction}

As in Study 1, we found that the degree of repugnance varied widely across the transactions studied (Figure 2). On average, the transactions were judged similarly repugnant in Studies 1 and 2: Medical marijuana, the second-least repugnant transaction in Study 1, was judged to be the least repugnant transaction $(M=1.56[1.23,1.92])$. As in Study 1, the right to hunt an endangered animal was judged to be the most repugnant transaction in the set $(M=5.95[5.70,6.12])$.

Also consistent with Study 1, we observed bimodal distributions of responses for the moderately repugnant transactions (on average, transactions were found to be moderately repugnant). These include selling horse meat in a restaurant $(M=3.03[2.51,3.56])$, selling the right to marry to a gay couple $([M=3.19[2.61,3.79])$, and selling an algorithm that can predict life expectancy $(M=3.48[2.99,4.00])$. The findings suggest that some trans-

actions are repugnant to everyone, whereas other transactions are approved of by some and disapproved of by others (Tetlock, 2003). The Supplementary Material (Section 5.2) lists coefficients for all transactions, ordered from least to most repugnant.

\section{Consistency Between Studies}

Overall, the mean judgments observed in Study 1 and 2 proved highly consistent. When ranking transactions in each study from the least to the most repugnant (see Supple- 


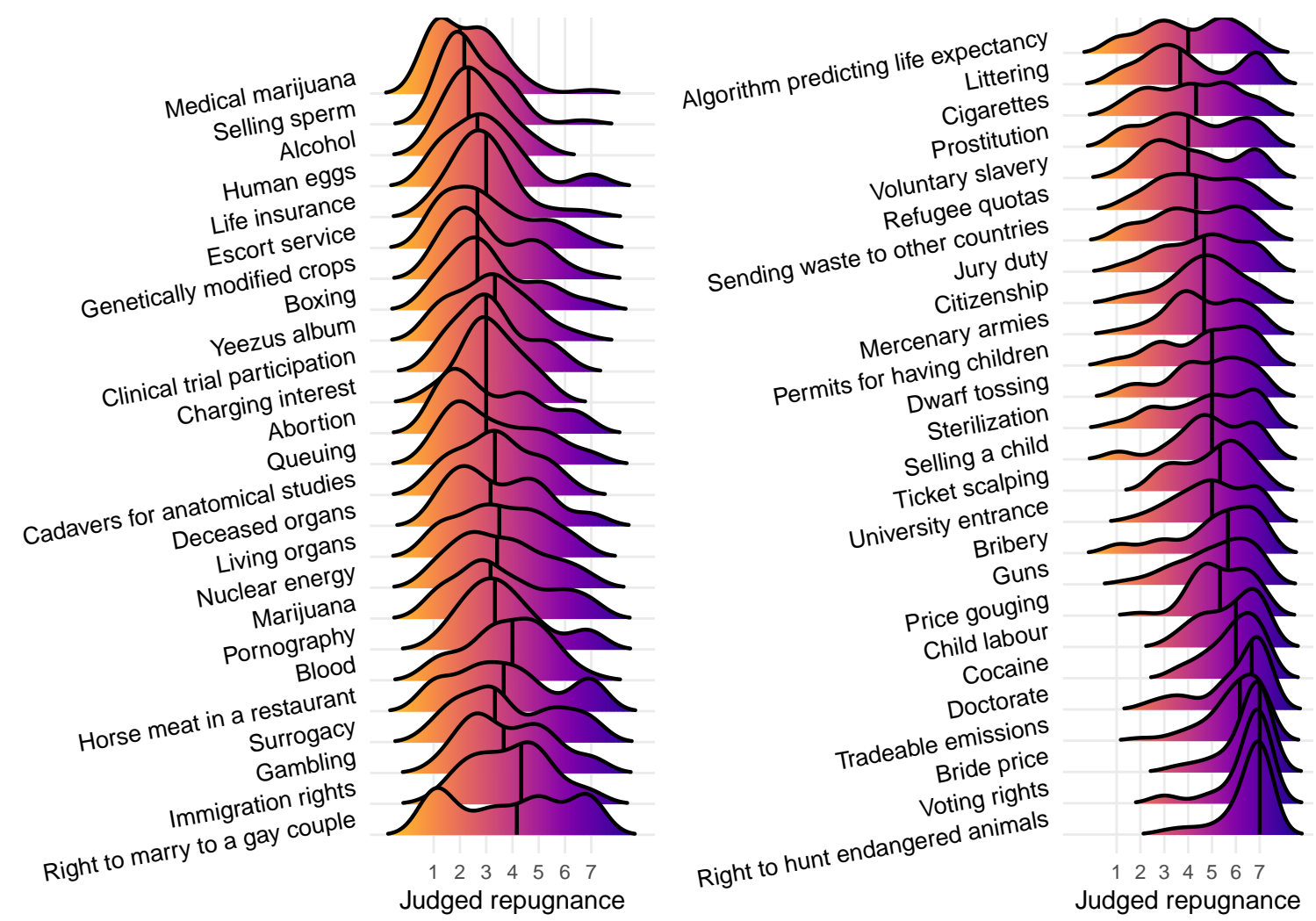

Figure 2. Judged repugnance across transactions (ordered from least to most repugnant transaction) in Study 2. Vertical lines represent median judgments across respondents.

mentary Material, Sections 5.1 and 5.2), we found high agreement between respondents in Study 1 (UK) and Study 2 (a wider range of countries), with a Spearman rank correlation $\rho=.92$ (Figure 3$)$.

\section{Dimensions (Replication of Study 1 Factors)}

A factor analysis replicates all five predicted factors (Table 3). As in Study 1, the most important factor is moral outrage. The higher a transaction's score on this factor, the more disgust and anger it triggers. Higher scores on this factor also indicate less empathy for the people engaged in the transaction, and more harm to society. The first factor also included two items that we originally predicted to load on other factors - the extent to which a transaction is considered taboo (suspected to load on "incommensurability) and the extent to which the transaction is unfair to the seller (suspected to load on "fairness"). Table 3 shows that these items have crossloadings with two other factors each. We recommend not including them in future studies. Also note that we relabelled this key factor moral outrage 


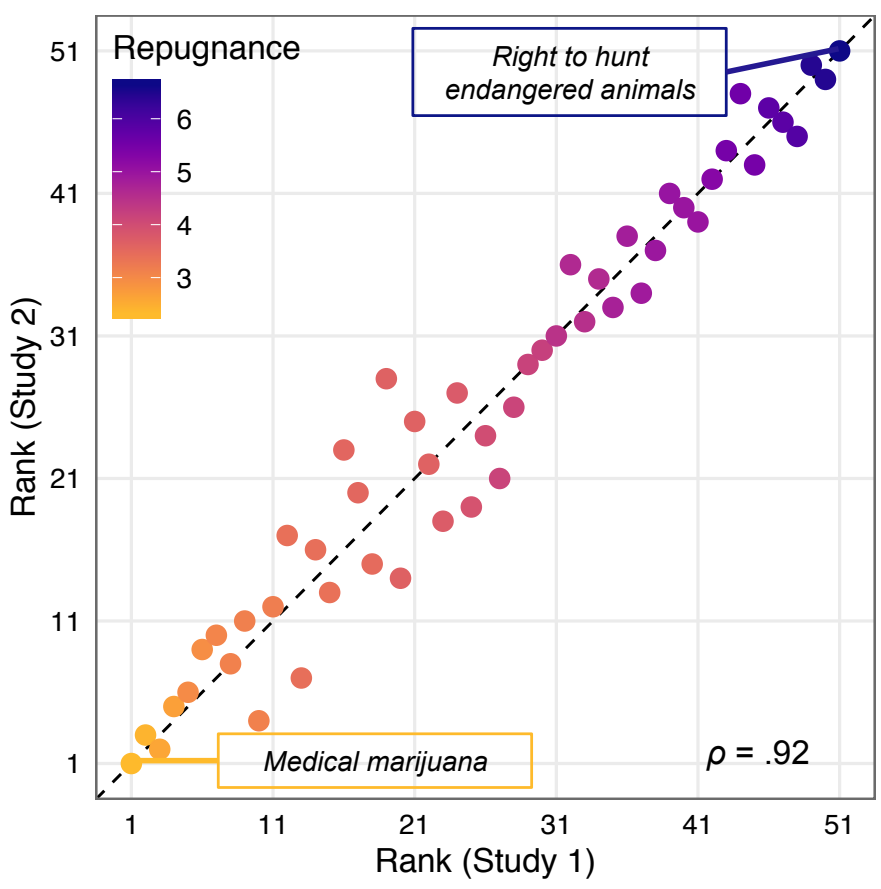

Figure 3. Rank order correlation between repugnance judgments in Study 1 versus Study 2. Each dot represents one of the 51 market transactions in the set. Transactions are ordered from least to most repugnant across both studies; deviations from the identity line indicate differences in rank orders between studies. Generally, the order of transactions from least to most repugnant is highly consistent between studies ( $\rho=.92$, with 1.0 indicating perfect agreement between samples).

(from moral disgust in Study 1) because two emotions, anger and disgust, loaded on this factor. Moral outrage - the interaction between anger and disgust (Salerno \& Peter-Hagene, 2013) - is a powerful emotion that "motivates people to shame and punish wrongdoers" (Crockett, 2017, p. 17). In the Sacred Value Protection Model, moral outrage is referred to as a "coping strategy" for judging taboo trade-offs (Tetlock et al., 2000).

The second factor, need for regulation, refers to the extent to which people want governments to regulate a transaction in question and to restrict it to the parties' home country. As predicted, a "buyer's risk to be sanctioned" now loads on this factor, likely because our set of transactions already included transactions that are currently regulated (e.g., gun trade, medical marijuana). The higher a transaction's score on the third factor, incommensurability, the more difficulty people have translating the transaction's worth into a monetary value and the more sacred they judge the good or service to be - and therefore, the less willing they will be to accept an exchange of money. The fourth factor, exploitation, describes the extent to which transactions are disadvantageous for people living in poverty 
Table 3

Final Five-Factor Model Solution

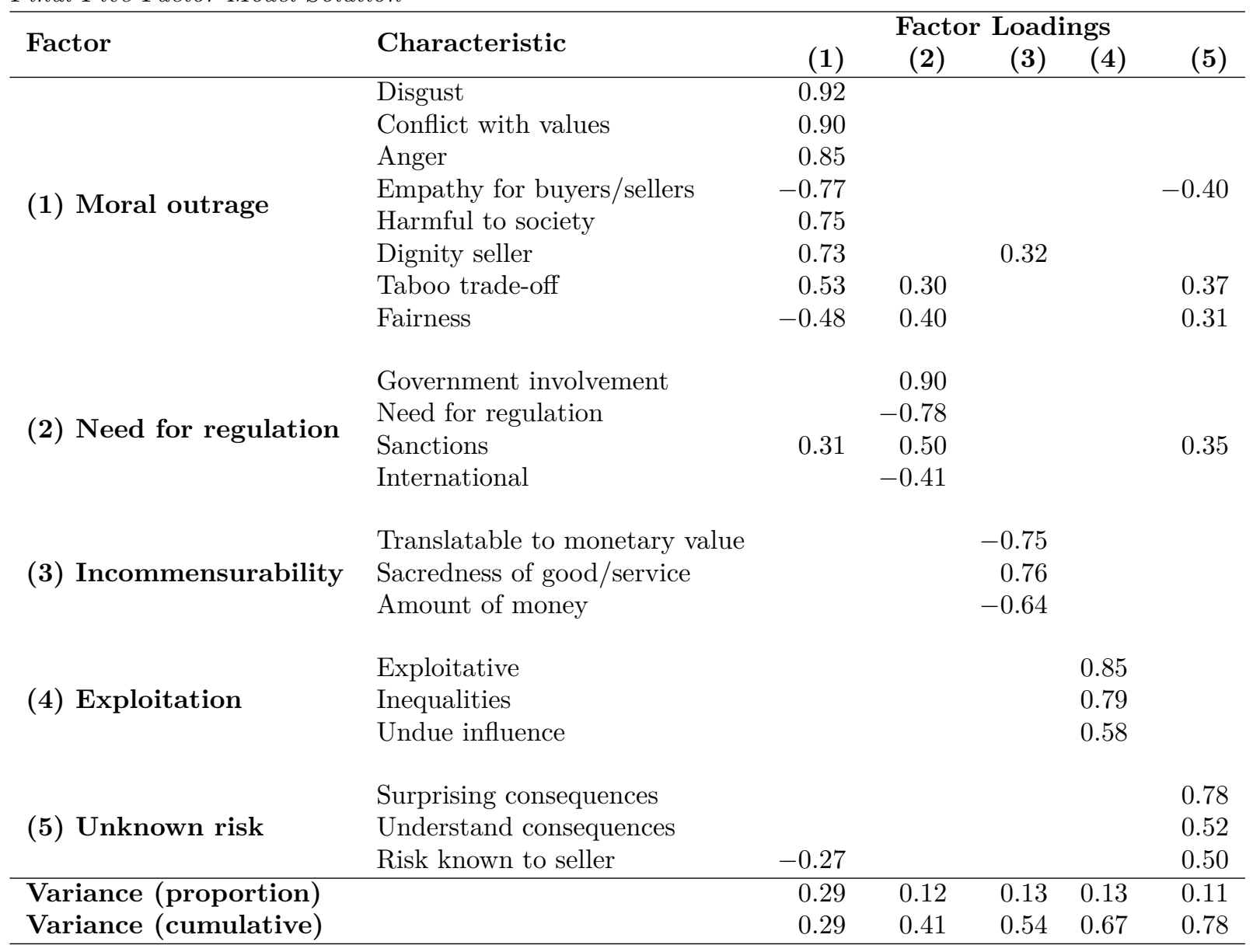

Note. Only loadings above .3 are displayed; characteristics are ordered based on their loadings to the five factors. We allowed for respondents' evaluations of various characteristics to be correlated (oblimin method).

by highlighting disparities between socioeconomic classes - for instance, it is unlikely that an affluent individual would feel financial pressure to sell their kidney. The final factor is unknown risk. The higher a transaction's score here, the more sellers are perceived as being exposed to unknown risks or as unable to fully anticipate the consequences of the transaction. The first factor, moral outrage, explains the largest proportion of variance in the data (.29). The remaining four factors each explain a similar proportion of variance (around .10). All factors consisted of three characteristics or more and had relatively few crossloadings. Most factors were moderately associated with each other (see Supplementary Material Section 6.6). Note that we explicitly allowed for factors and properties to be correlated (by choosing an oblique method to rotate extracted factors) because of theoretical 
considerations - transactions that trigger moral outrage will likely also elicit a need for regulation. As a robustness check, we also ran a confirmatory factor analysis using the lavaan package in $\mathrm{R}$ (Rosseel, 2012). This analysis provided further evidence for the factor structure reported above (see Supplementary Material Section 6.8).

Figure 4 plots all 51 transactions in a factor space made up of two of the five factors, moral outrage and the need for regulation. This factor space shows that many transactions that trigger substantial moral outrage also trigger a strong perceived need for regulation (upper right quadrant). This echoes the finding that the higher the dread potential of a risk, the more people want it to be strictly regulated (Slovic, 1987). However, some transactions elicit little moral outrage but are still associated with a strong need for regulation (upper left quadrant). Surrogate motherhood, organ donations from deceased donors, and offering abortions fall into this category. The figure illustrates that repugnance can be broken down into different factors - such as moral outrage and the need for regulation - and that not all characteristics are perceived as equally pronounced across different transactions.

\section{Profiles of Repugnant Transactions}

Figure 5 plots each transaction's scores on all five factors, ordered from least repugnant (top left: medical marijuana) to most repugnant (bottom right: right to hunt an endangered animal). All factor scores are based on normalized values. Consequently, deviations from 0 indicate the transaction scores higher or lower on a particular factor relative to the other transactions in the set. The figure reveals two interesting aspects of these profiles of repugnant transactions.

First, the most repugnant transaction in the set-the right to hunt an endangered animal - scores higher than the average transaction does on most dimensions. Consistent with media reports (e.g., Herskovitz, 2014), the right to hunt an endangered animal cooccurs with high moral outrage, the need for regulation, and some degree of incommensurability. This transaction is also deemed exploitative, and thought to expose the seller to unknown risks. Conversely, many of the least repugnant transactions (e.g., the sale of medical marijuana or alcohol) score lower than the average transaction on all or four of the five factors. A regression analysis revealed that all factors were positively associated with judged repugnance $\left(b_{\text {moral outrage }}=1.04[0.95,1.13], b_{\text {need for regulation }}=0.45[0.16,0.74]\right.$, $b_{\text {incommensurability }}=0.39[0.10,0.68], b_{\text {exploitation }}=0.53[0.25,0.80], b_{\text {unknown risk }}=0.38$ 


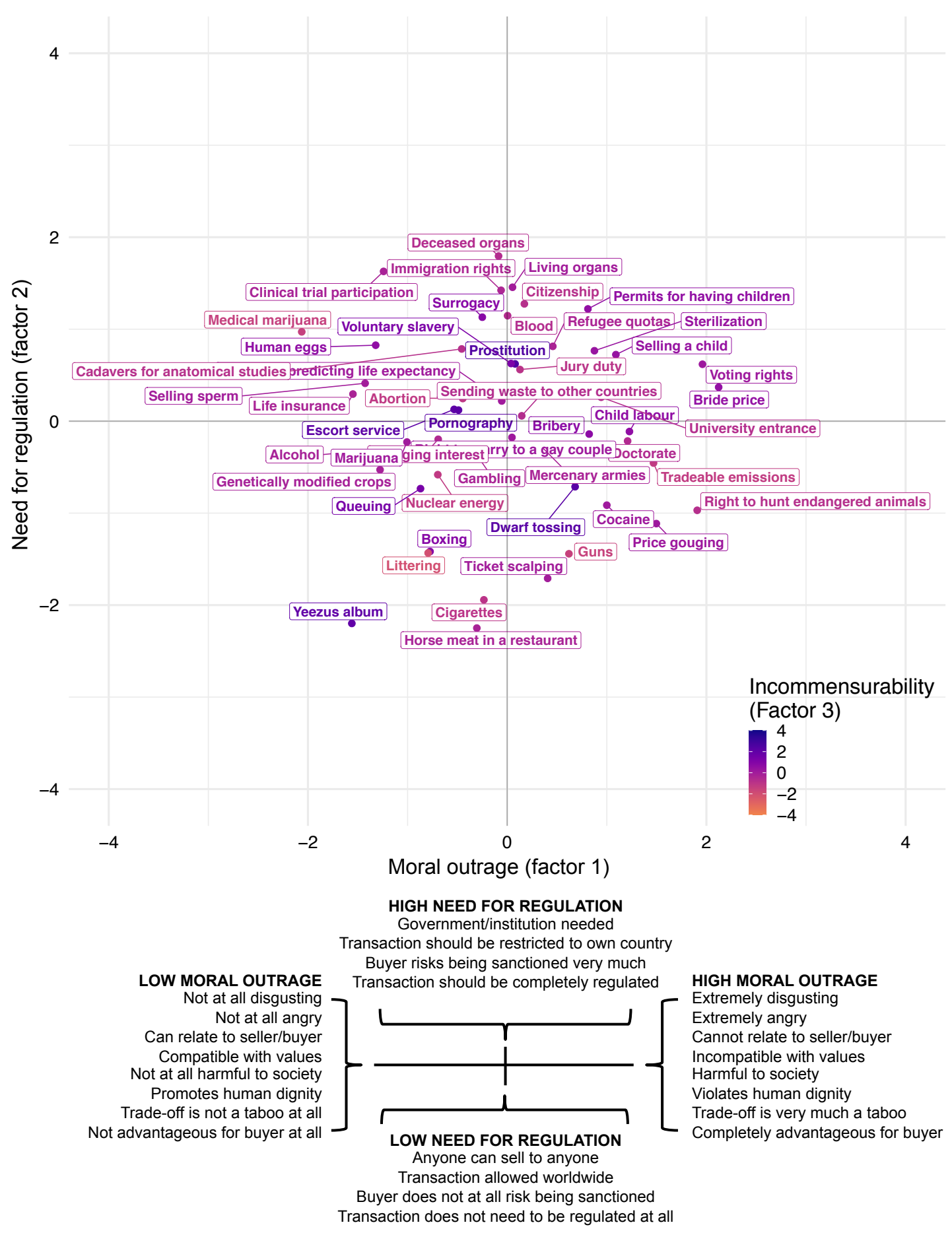

Figure 4. Location of 51 transactions on factors 1 (moral outrage) and 2 (need for regulation) derived from the relationship among 22 characteristics of repugnant transactions. Each factor consists of a combination of characteristics, as shown below the x-axis. Color denotes factor 3 (incommensurability). 
$[0.08,0.67])$. These associations are imperfect: As Figure 5 also shows, different factors matter more or less in explaining repugnance for different transactions - which is unsurprising given the wide range of transactions sampled for the current studies. The Supplementary Material (Section 6.5) shows that most of the factors were also imperfectly correlated with each other. This is a consequence of theoretical considerations (a transaction may trigger more moral outrage and a higher need for regulation if it is more exploitative).

Second, consistent with this analysis, each transaction's profile is unique (Figure 5). Notably, factor scores across transactions are highly variable for the moderately repugnant transactions, while overall judged repugnance is not. For instance, clinical trial participation induced little moral outrage but was considered somewhat exploitative, and judged to expose volunteers to unknown risks (consistent with earlier research; Leuker et al., 2020). A rapper selling an album named "Yeezus" was judged to be the most commensurable with money and the least exploitative of all transactions in the set. Surrogate motherhood was characterized more by the unknown risk to women than by its potentially exploitative nature, and was considered only somewhat incommensurable with money (but not much more than the average transaction in the set). Dwarf tossing and selling permits for having children were considered similarly repugnant on average, yet Figure 5 reveals that the desire to regulate (or perhaps prohibit) permits for having children is much higher than the desire to regulate dwarf tossing, even though both transactions trigger high moral outrage. Permits for having children are also considered more incommensurable with money than dwarf tossing. Identifying the dimensions that primarily shape perceptions of a given transaction can offer proponents and opponents of a particular market a valuable common starting point for productive public discourse.

\section{Conclusion}

Morally contested market transactions can be described on five distinct dimensions: moral outrage, need for regulation, incommensurability, exploitation, and unknown risk. All are associated with the extent to which market transactions were perceived as repugnant. Moreover, we found a similar rank order of the extent to which market transactions are considered repugnant across two studies. The five dimensions can be used to create profiles for each transaction and compare people's perceptions across transactions. While transactions that are considered extremely repugnant appear to score high on each of the 


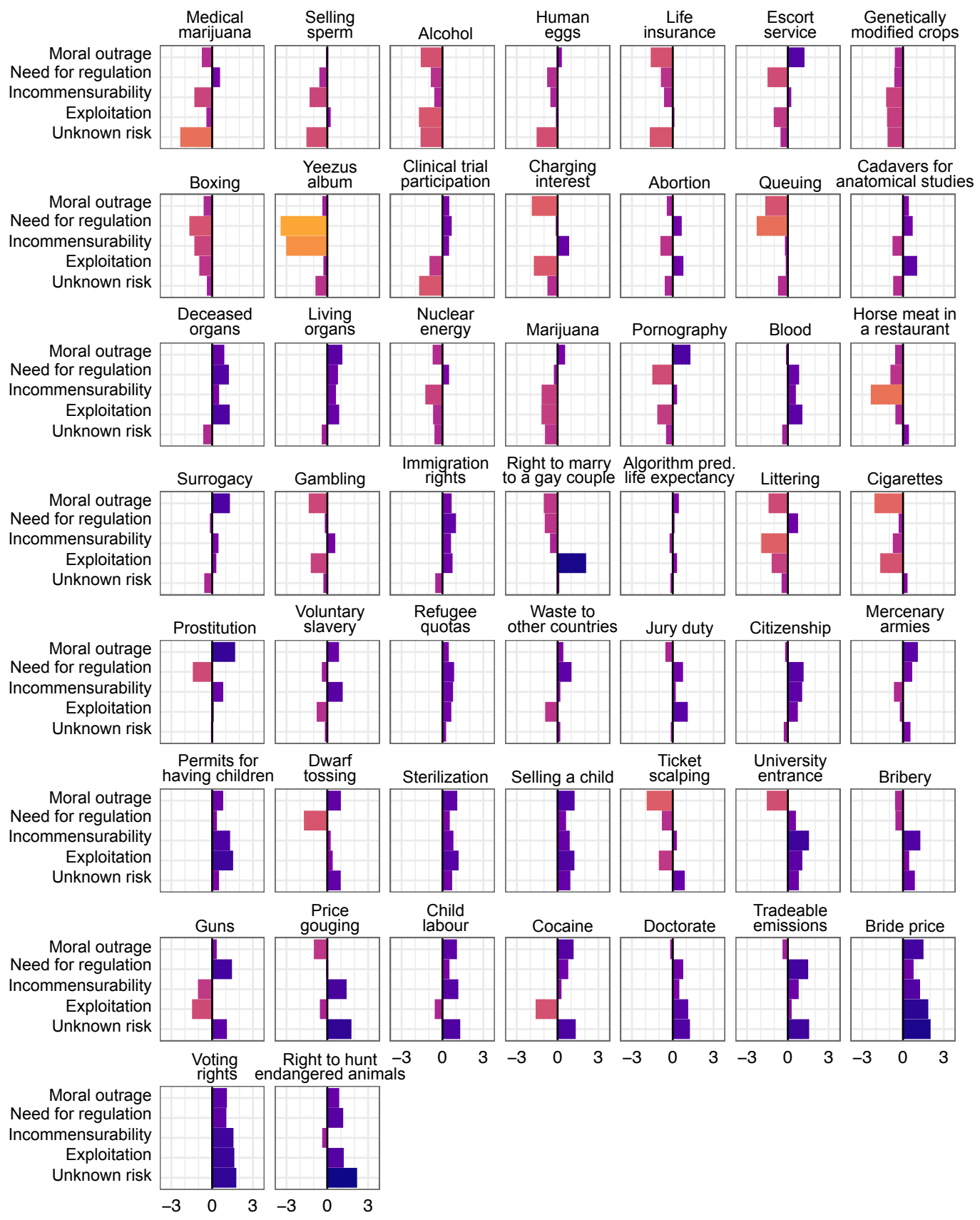

Factor Score

Figure 5. Profiles of all 51 transactions on across the five factors, ordered from least repugnant (medical marijuana) to most repugnant (right to hunt an endangered animal) in the set. All factor scores are based on normalized values; deviations from 0 indicate the transaction scores higher or lower on a particular factor relative to the other transactions in the set.

five factors, perceptions vary for moderately repugnant transactions. 


\section{General Discussion}

Many people find markets for body parts, sex, companionship, and civil duties repugnant (Roth, 2007). Repugnance has often been studied separately within each of these domains, but not across them, making it difficult to gain a clearer understanding of the shared dimensions of repugnant transactions. Since this understanding is arguably crucial for reliably predicting how people might respond to novel kinds of market transactions, we aimed to shine a light on the deep grammar of repugnance in transactions.

First, we found that 25 characteristics previously identified in the study of repugnant transactions can be distilled into five distinct psychological dimensions: moral outrage, need for regulation, incommensurability, exploitation, and unknown risk. Classifying the multifaceted nature of repugnance into a handful of dimensions provides a structure that can, for the time being, be hypothesized to represent its deep grammar. Second, we were able to both quantify the extent to which a total of 51 transactions are considered to be repugnant and to describe the notable heterogeneity in the extent to which these transactions trigger repugnant feelings. Some transactions scored high on all or most of the five dimensions (e.g., right to hunt endangered animals, bride price); others scored high on only one or two dimensions (e.g., escort service, pornography; see Figure 5).

Importantly, respondents' average judgments of repugnance proved highly consistent across both studies. At the same time, there was substantial individual variability in how people assessed some of the moderately repugnant transactions (e.g., surrogate motherhood, horse meat in a restaurant, algorithms predicting life expectancy). This suggests that some types of transactions are "on ideological fringes," inducing approval in some individuals and opposition in others (Tetlock, 2003, p. 321). Third, we identified the extent to which each of the identified dimensions contributes to feelings of repugnance for each transaction. Transactions' scores on the five factors can be used to create unique profiles for market transactions - thereby revealing, for example, whether a particular transaction is seen as incommensurable, exploitative, or both. This shows how transactions that, on average, prompt the same or similar degrees of repugnance may do so for very different reasons. Relatedly, a close comparison of transactions in Figure 5 suggests that factors other than those identified in this work may contribute to global judgments of repugnance. For instance, selling cigarettes is considered slightly more repugnant than selling an algorithm predicting life expectancy - yet, selling cigarettes scores lower on most of the five factors than the 
algorithm. Future research should seek to identify factors that account for such differences.

Fourth, we identified mismatches between judged repugnance of a transaction and its current legal status. For instance, respondents considered carbon emissions trading and selling permits to shoot rare animals highly repugnant, but both are legal. Such mismatches may be grounds for policy makers to reevaluate those transactions (also see Roth \& Wang, 2020); however, it is worth noting that legalization does not necessarily need to reflect the sentiments of the majority (e.g., if the trade in question affects a group of people who disagree with the majority on the transaction's repugnance). Finally, we observed that the degree of moral outrage a transaction prompts is a good predictor for the desire for regulation (comparable to "dread risk" in the case of desired regulation of risks Slovic, 1987), even though notable exceptions exist in which regulation is desired in the absence of moral outrage (e.g., surrogate motherhood, organ donations from deceased donors).

Let us also highlight some of the limitations of our investigation. Even though we replicated the factor structure in two studies, the factor space needs to be replicated in different groups of respondents (e.g., respondents with different educational backgrounds, respondents with different cultural backgrounds, laypeople vs. experts). Culture-specific sets of transactions could also be examined (our studies used an encompassing and diverse global set of transactions). The factor structure we identified is robust and informative, but detailed replication studies are necessary to capture the cognitive mapping of the domain of repugnant transactions across an even wider range of transactions and populations. Moreover, our studies represent a snapshot in time and cannot capture how perception of repugnance may change across time and locations (for an excellent analysis of historical case studies see Frevert et al., 2019). Next, in identifying characteristics that can induce repugnance, we harnessed the existing literature. Our set of characteristics is by no means exhaustive, and characteristics and factors other than those we identified may cause people to oppose certain types of transactions. Last but not least, our sample size, for the purpose of conducting factor analyses, was relatively small, thereby possibly limiting the robustness of the obtained factor structure even though the factor structure was replicated independently. With these qualifications in mind, we now turn to implications of our findings.

How does a transactions' legal status relate to its factor-analytic representation? In Figure 6, we plot the transactions' positions in a factor space made of two factors, moral outrage (factor 1) and incommensurability (factor 2, denoting the degree to which the 
exchange of money for the entity traded is considered acceptable in a transaction). The color of a point represents a transaction's actual legal status in the UK at the time of writing and the point's size represents the strength of the desire to forbid the transaction. In general, transactions that score high on the factors moral outrage and incommensurability invoke a stronger desire to forbid. Many of these transactions are also illegal. This is most pronounced in the upper right cell, where transactions that score high on both factors cluster (e.g., child labor, dwarf tossing, the sale of voting rights). However, Figure 6 also reveals a few transactions that score high on moral outrage and are legal, such as the right to hunt an endangered animal and trading carbon emissions. High moral outrage for transactions that are currently legal signals that public acceptance of the policy in place is threatened, or that public attitudes are polarized. This could necessitate measures such as reconsidering the transaction's legal status or improving communication around the rationale associated with a policy (e.g., the carbon emission trade as a tool for reducing carbon emissions). The transaction-specific profiles plotted in Figure 5 can pinpoint why a particular transaction is considered repugnant. They also show that similar degrees of mean repugnance can emerge for different reasons. Consider prostitution and the sale of citizenship: Both are considered similarly repugnant, but prostitution scores high on moral outrage and low on the need for regulation, while the sale of citizenship scores low on moral outrage but high on the need for regulation. The kinds of profiles plotted in Figure 5 help identify the hot buttons a transaction may or may not push and thus guide public and legal discourse on these transactions. 


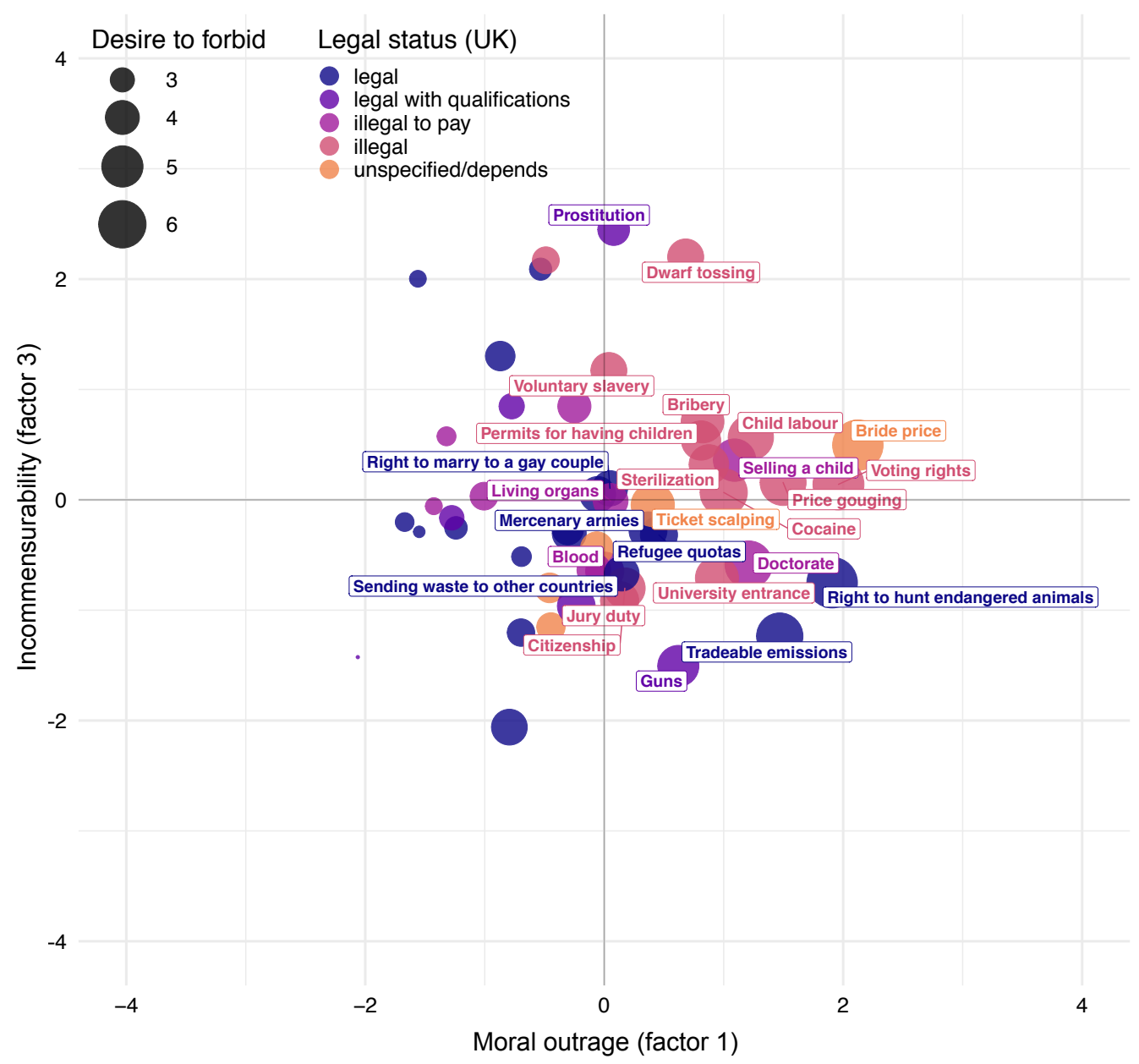

Figure 6. Location of transactions on factors 1 (moral outrage) and 2 (incommensurability). Transactions are also categorized depending on their legal status in the UK (see color coding) and the desire to forbid (the larger the point, the greater the desire for banning the transaction). Only transactions with moral outrage $>0$ are labelled for clarity.

What we have learned about the nature of repugnance? Roth (2007) called on economists "to understand better and engage more with the phenomenon of repugnant transactions. Attitudes about the repugnance (or other kinds of inappropriateness) of transactions shape whole markets, and therefore shape what choices people face" (p. 38). However, he also highlighted that "predicting when repugnance will play a decisive role is difficult, because apparently similar activities and transactions are often judged differently" (p. 43). In principle, there are at least two distinct ways to better understand why a market activity is perceived as repugnant or not. One is to thoroughly dissect a specific transaction, isolate its key properties, and experimentally investigate how removing or adding these properties changes feelings of repugnance. While insightful for a specific transaction, this 
approach ultimately leaves researchers with a long list of characteristics that are deemed crucial. For instance, we identified a total of 25 characteristics based on past research. An unwieldy list makes it increasingly hard to see the forest for the trees; nor does it necessarily improve the accuracy of predictions about repugnance.

A second approach is comparative and aims to understand what common grammar might underlie repugnant transactions. This is the approach we took here. We adopted the "psychometric paradigm" that Slovic (1987) and colleagues have successfully established in the investigation of public perception of risk. Their goal was to develop a taxonomy of hazards that, in turn, can be used to understand and even predict responses to their risks. "A taxonomic scheme might explain, for example, people's extreme aversion to some hazards, their indifference to others, and the discrepancies between these reactions and the opinions of experts" (Slovic, 1987, p. 281). This description of the seeming incoherence of people's responses to hazards and their risks echoes the elusive nature of repugnance in transactions. The psychometric paradigm enabled us to take an important step toward predicting when repugnance will emerge. We found that when a transaction scores high on strong moral outrage, need for regulation, incommensurability, exploitation, and unknown risk, people are very likely to perceive it as repugnant. We also found, in both of our studies, that moral outrage explained the largest proportion of variance in the data. This suggests, at least initially, that the essence of repugnance may be a strong emotional response. An emotionally rooted opposition to a concept or idea would indeed be consistent with previous accounts (e.g., Ekman, 2016; Kass, 1997). For instance, according to Kass (1997), repugnance can be "an emotional expression of deep wisdom, beyond reason's power to fully articulate it" (p. 17). In addition, moral outrage has been conceived as a powerful emotion that leads people to shame and punish wrongdoers in their community (Crockett, 2017; Tetlock, 2003). One may thus be tempted to think of moral outrage as adaptive and in our analyses, it is indeed elicited by transactions perceived to be harmful to society. Other scholars, however, have highlighted that moral outrage as a gut response and in the absence of other reasons for objecting to a transaction can exact substantial negative consequences (e.g., supporting sexism or bigotry, Nussbaum, 2010), including tempting people toward moral grandstanding (Baier, 1960).

Implications for policy makers. Roth's (2007) observation that repugnance can emerge in many markets has prompted debates about how these markets should be regulated. Anal- 
yses such as ours that shed light on the diverse sources of repugnance can make these debates more productive. For instance, some transactions are seen as entailing high unknown risk but do not provoke moral outrage; others provoke significant moral outrage but are not seen as entailing exploitation or unknown risk (Figure 5). Distinct commonalities and differences can be used to identify, as (Roth, 2007) put it, "issues that are fundamentally empirical ... from areas of disagreement that are not primarily empirical" (p. 54). For instance, if the key concern is that a transaction entails unknown risk, it can be made less repugnant by regulating the conditions of the transaction, thereby reducing the risk as much as possible (this is the case for, e.g., clinical trials; see Leuker et al., 2020). If risk reduction is not possible, another approach to reducing public concern could involve transparently communicating the risks. As people feel better informed about the risks, they may be more willing to approve of certain market transactions (Schmidt, 2019).

Alternatively, repugnance in a transaction may stem from the fact or perception that the transaction is exploitative. If so, policy interventions could aim to protect those who are at risk of being exploited. For instance, selling kidneys on the free market is considered exploitative by most; it is also prohibited in most countries. One way to address this concern is to redesign the market such that kidney donations can be swapped between compatible donors (typically patients' friends or family members whose kidney is incompatible with their loved one). These paired donations are not perceived as exploitative and have been instrumental in increasing kidney transplantation rates (Wallis et al., 2011).

In considering the public discussion of specific potentially repugnant market transactions, it is helpful to keep in mind that there are transactions-including the sale of horse meat in a restaurant, algorithms predicting life expectancy, the sale of cigarettes, and the export of waste to other countries - that elicit strong repugnance in some, but not all, respondents. This may be due to individual characteristics of the respondents themselves. For instance, the best single predictors for repugnance in both studies was disgust, which is part of moral outrage. Sensitivity to disgust varies across individuals; for instance, women have been found to be more easily morally disgusted than men, though evidence is mixed (Al-Shawaf et al., 2015, 2018; Tybur et al., 2009). It is also possible that the source of interindividual differences resides in the interaction between a particular transaction and individual characteristics (Roth \& Wang, 2020). Whatever the reason, understanding what causes polarized attitudes toward specific transactions is likely to foster more constructive 
public debate.

Roth (2007) noted that economists and proponents of controversial markets such as kidney sales do not always take repugnance seriously enough. One benefit of our approach of identifying the deep grammar of repugnant market transactions is to facilitate serious discussions between advocates for and opponents of specific controversial market transactions by permitting both sides to better engage with the cause of feelings of repugnance and to clarify whether and how these feelings might be concretely addressed. This kind of informed discussion could lead to an appropriately regulated market - or to the conclusion that the concerns voiced cannot be addressed by regulation. It is important to note that the rise of polarization and the spread of misinformation and conspiracy theories has undermined many people's trust in evidence and, as a result, added further complications to public discourse over controversial issues (see Kozyreva et al., 2020). This does not mean, however, that all is lost. Rather, it is more important than ever to forge fundamental connections between sides. We believe that pinpointing the sources of repugnance can help establish crucial common ground in polarized discussions about controversial markets.

\section{Conclusion}

Our studies show that sources of repugnance can be revealed. Gaining insight into psychological dimensions that underlie repugnant transactions may facilitate constructive discussions between proponents and opponents of a specific market. The factor space we identified is robust across two studies and informative; future research should aim to determing the extent to which it generalizes to other places, times, and sets of markets. 
Author contributions: Conceptualization: C.L., L.S., \& R.H.; Methodology: C.L., L.S., \& R.H.; Software: L.S.; Data collection \& curation: L.S. (Study 1) \& C.L. (Study 2); Formal analysis: C.L. \& L.S.; Writing — original draft: C.L.; Writing — reviewing \& editing: C.L., L.S., \& R.H. All authors approved the final version of the manuscript for submission.

Acknowledgments: We thank Ruben Arslan, Nadine Fleischhut, Jan K. Woike, and the rest of the Center for Adaptive Rationality for useful discussions, and Deb Ain for editing the manuscript.

Open Practices Statement: Data and analysis code can be retrieved via the Open Science Framework (osf.io/efzsm).

Conflicts of interest: None. 
References

Al-Shawaf, L., Lewis, D. M. G., \& Buss, D. M. (2015). Disgust and mating strategy. Evolution and Human Behavior, 36(3), 199-205. doi: 10.1016/j.evolhumbehav.2014.11 .003

Al-Shawaf, L., Lewis, D. M. G., \& Buss, D. M. (2018). Sex differences in disgust: Why are women more easily disgusted than men? Emotion Review, 10(2), 149-160. doi: $10.1177 / 1754073917709940$

Ambuehl, S. (2017). An offer you can't refuse? Incentives change what we believe. SSRN. doi: $10.2139 / \operatorname{ssrn} .2830171$

Ambuehl, S., Niederle, M., \& Roth, A. E. (2015). More money, more problems? Can high pay be coercive and repugnant? American Economic Review, 105(5), 357-360. doi: 10.1257/aer.p20151034

Ambuehl, S., \& Ockenfels, A. (2017). The ethics of incentivizing the uninformed: A vignette study. American Economic Review, 107(5), 91-95. doi: 10.1257/aer.p20171109

Baier, K. (1960). The Moral Point of View: A Rational Basis of Ethics. The Philosophical Review. doi: 10.2307/2183493

Ball, P. (2018, November 19). Super-smart designer babies could be on offer soon. But is that ethical? The Guardian. Retrieved from www.theguardian.com/commentisfree/ 2018/nov/19/designer-babies-ethical-genetic-selection-intelligence

Briseño, C. (2018). Ethics of algorithms. Retrieved from https://ethicsofalgorithms .org/2018/09/19/optimizing-palliative-care-when-algorithms-predict-a -patients-death/

Bruneau, E. G., Cikara, M., \& Saxe, R. (2017). Parochial empathy predicts reduced altruism and the endorsement of passive harm. Social Psychological and Personality Science, 8(8), 934-942. doi: 10.1177/1948550617693064

Bürkner, P.-C. (2017). brms: An R package for Bayesian multilevel models using Stan. Journal of Statistical Software, 80. doi: 10.18637/jss.v080.i01 
Bürkner, P.-C., \& Vuorre, M. (2018). Ordinal regression models in psychology: A tutorial. Advances in Methods and Practices in Psychological Science, 2(1), 77-101. doi: 10.1177/ 2515245918823199

CBC. (2012, January 27). Dwarf tossing draws outrage. Retrieved from https://www.cbc .ca/news/canada/windsor/dwarf-tossing-draws-outrage-1.1236537

Chivers, C. J. (2002, August 25). A big game. The New York Times Magazine. Retrieved from https://www.nytimes.com/2002/08/25/magazine/a-big-game.html

Costello, A. B., \& Osborne, J. W. (2005). Best practices in exploratory factor analysis: Four recommendations for getting the most from your analysis. Practical Assessment, Research, ES Evaluation, 10(7).

Crockett, M. J. (2017). Moral outrage in the digital age. Nature Human Behaviour, 1, 769-771. doi: 10.1038/s41562-017-0213-3

Decker, O., Winter, M., Brähler, E., \& Beutel, M. (2008). Between commodification and altruism: Gender imbalance and attitudes towards organ donation. A representative survey of the German community. Journal of Gender Studies, 17(3), 251-255. doi: $10.1080 / 09589230802204290$

Ekman, P. (2016). Disgust. Retrieved from http://atlasofemotions.org/\#states/ disgust (Accessed: 2020-03-04)

Elias, J. J., Lacetera, N., \& Macis, M. (2015). Sacred values? The effect of information on attitudes toward payments for human organs. American Economic Review, 105(5), 361-365. doi: 10.1257/aer.p20151035

Elias, J. J., Lacetera, N., \& Macis, M. (2016). Efficiency-morality trade-offs in repugnant transactions: A choice experiment [NBER Working Paper No. 22632]. Cambridge, MA: National Bureau of Economic Research. Retrieved from http://www.nber.org/papers/ w22632

Elias, J. J., Lacetera, N., Macis, M., \& Salardi, P. (2017). Economic development and the regulation of morally contentious activities. American Economic Review, 107(5), 76-80. doi: $10.1257 /$ aer.p20171098 
Ezell, A., \& Bear, J. (2005). Degree mills: The billion-dollar industry that has sold over a million fake diplomas. Amherst, NY: Prometheus Books.

Fiske, A. P., \& Tetlock, P. E. (1997). Taboo trade-offs: Reactions to transactions that transgress the spheres of justice. Political Psychology, 18(2), 255-297. doi: 10.1111/ 0162-895X.00058

Frevert, U., Fontaine, L., Suter, M., Danilina, A., Blass, B., Rohringer, T., ... Fourcade, M. (2019). Moral economies. Vandenhoeck \& Ruprecht.

Frey, B. S., \& Jegen, R. (2001). Motivation crowding theory. Journal of Economic Surveys, 15(5), 589-611. doi: 10.1111/1467-6419.00150

Frey, B. S., \& Oberholzer-Gee, F. (1997). The cost of price incentives: An empirical analysis of motivation crowding-out. American Economic Review, 87(4), 746-755.

Gelman, A., \& Rubin, D. B. (1992). Inference from iterative simulation using multiple sequences. Statistical Science, 7(4), 457-511. doi: 10.1214/ss/1177011136

Ghods, A. J., \& Savaj, S. (2006). Iranian model of paid and regulated living-unrelated kidney donation. Clinical Journal of the American Society of Nephrology, 1(6), 11361145. doi: 10.2215/CJN.00700206

Goette, L., \& Stutzer, A. (2020). Blood donations and incentives: Evidence from a field experiment. Journal of Economic Behavior $\&$ Organization.

Goff, S. H., \& Noblet, C. L. (2018). Efficient, but immoral? Assessing market attitudes as multidimensional. Economics Letters, 170, 96-99. doi: 10.1016/j.econlet.2018.05.020

Hammond, S. (2018, September 12). How Iran Solved Its Kidney Shortage, And We Can Too. [Blog Post, Niskanen Center]. Retrieved from https://www.niskanencenter.org/ how-iran-solved-its-kidney-shortage-and-we-can-too/

Hercher, L. (2018). Designer babies aren't futuristic. They're already here. Retrieved from https://www.technologyreview.com/s/612258/are-we-designing-inequality -into-our-genes/ 
Herskovitz, J. (2014, January 11). Permit to hunt endangered rhino sells for $\$ 350,000$ despite protests. Scientific American. Retrieved from https://www.scientificamerican.com/ article/permit-to-hunt-endangered-rhino-sel/ (Accessed: 2019-10-23)

Hill, J. L. (1994). Exploitation. Cornell Law Review, 79(3), 631-699.

Kahneman, D., Knetsch, J. L., \& Thaler, R. (1986). Fairness as a constraint on profit seeking: Entitlements in the market. American Economic Review, 76(4), 728-741. doi: $10.2307 / 1806070$

Kass, L. R. (1997). The Wisdom of Repugnance. The New Republic.

Khalil, E. L., \& Marciano, A. (2018). A theory of tasteful and distasteful transactions. Kyklos, $71(1), 110-131$. doi: 10.1111/kykl.12164

Kozyreva, A., Lewandowsky, S., \& Hertwig, R. (2020). Citizens versus the internet: Confronting digital challenges with cognitive tools. Psychological Science in the Public Interest, $21(3), 103-156$.

Kruschke, J. K. (2014). Doing Bayesian data analysis: A tutorial with R, JAGS, and Stan, 2nd ed. New York, NY: Academic Press.

Lacetera, N. (2017). Incentives and ethics in the economics of body parts. Osgoode Hall Law Journal, 54(2), 397-417.

Lee, L., Piliavin, J. A., \& Call, V. R. (1999). Giving time, money, and blood: Similarities and differences. Social psychology quarterly, 276-290.

Leider, S., \& Roth, A. E. (2010). Kidneys for sale: Who disapproves, and why? American Journal of Transplantation, 10(5), 1221-1227. doi: 10.1111/j.1600-6143.2010.03019.x

Leuker, C., Samartzidis, L., Hertwig, R., \& Pleskac, T. J. (2020). When money talks: Judging risk and coercion in high-paying clinical trials. PloS ONE, 15(1), e0227898. doi: 10.1371/journal.pone.0227898

Niederle, M., \& Roth, A. E. (2014). Philanthropically funded heroism awards for kidney donors? Law and Contemporary Problems, 77, 131-144. 
Niederle, M., Roth, A. E., \& Sonmez, T. (2008). Matching and market design. In S. Derlauf \& L. Blume (Eds.), The new Palgrave dictionary of economics, 2nd ed. Hampshire, United Kingdom: Palgrave Macmillan. doi: 10.1057/9780230226203.1058

Nussbaum, M. C. (2010). From disgust to humanity: Sexual orientation and constitutional law. New York, NY: Oxford University Press.

Premalatha, M., Abbasi, T., Abbasi, T., \& Abbasi, S. A. (2011). Energy-efficient food production to reduce global warming and ecodegradation: The use of edible insects. Renewable and Sustainable Energy Reviews, 15(9), 4357-4360. doi: 10.1016/j.rser.2011 .07 .115

Querido, S., Weigert, A., Adragão, T., Machado, D., \& Pais, D. (2019). Rewards to increase living kidney donation: The state of the art. Nefrologia, 39(1), 11-14. doi: 10.1016/j.nefroe.2018.08.002

Quezada, M. S., Gil, M. M., Francisco, C., Oròsz, G., \& Nicolaides, K. H. (2015). Screening for trisomies 21, 18 and 13 by cell-free DNA analysis of maternal blood at 10-11 weeks' gestation and the combined test at 11-13 weeks. Ultrasound in Obstetrics and Gynecology, 45(1), 36-41. doi: 10.1002/uog.14664

Rahwan, I., Cebrian, M., Obradovich, N., Bongard, J., Bonnefon, J.-F., Breazeal, C., ... Wellman, M. (2019). Machine behaviour. Nature, 568(7753), 477-486. doi: 10.1038/ s41586-019-1138-y

Revelle, W. (2018). psych: Procedures for psychological, psychometric, and personality research [Computer software manual]. Evanston, Illinois. Retrieved from https://CRAN .R-project.org/package=psych (R package version 1.8.10)

Rodrigue, J. R., Crist, K., Roberts, J. P., Freeman Jr, R. B., Merion, R. M., \& Reed, A. I. (2009). Stimulus for organ donation: A survey of the American Society of Transplant Surgeons membership. American Journal of Transplantation, 9(9), 2172-2176. doi: 10 $.1111 / \mathrm{j} .1600-6143.2009 .02741 . \mathrm{x}$

Rosseel, Y. (2012). lavaan: An R package for structural equation modeling. Journal of Statistical Software, 48(2), 1-36. Retrieved from http://www.jstatsoft.org/v48/ i02/ 
Roth, A. E. (2007). Repugnance as a constraint on markets. Journal of Economic Perspectives, $21(3)$, 37-58. doi: 10.1257/jep.21.3.37

Roth, A. E. (2015). Who gets what and why: The hidden world of matchmaking and market design. London, United Kingdom: William Collins.

Roth, A. E., \& Wang, S. W. (2020). Popular repugnance contrasts with legal bans on controversial markets. Proceedings of the National Academy of Sciences.

Rouchi, A. H., Ghaemi, F., \& Aghighi, M. (2014). Outlook of organ transplantation in Iran: A time for quality assessment. Iranian Journal of Kidney Diseases, 8(3), 185-188.

Salerno, J. M., \& Peter-Hagene, L. C. (2013). The interactive effect of anger and disgust on moral outrage and judgments. Psychological Science, 24(10), 2069-2078. doi: 10.1177/ 0956797613486988

Sandel, M. J. (2012). What money can't buy: The moral limits of markets. New York, NY: Farrar, Straus and Giroux.

Sandel, M. J. (2013). Market reasoning as moral reasoning: Why economists should reengage with political philosophy. Journal of Economic Perspectives, 27(4), 121-140. doi: $10.1257 /$ jep.27.4.121

Sanders, T. (2004). The risks of street prostitution: Punters, police and protesters. Urban Studies, 41(9), 1703-1717. doi: 10.1080/0042098042000243110

Satz, D. (2010). Why some things should not be for sale: The moral limits of markets. New York, NY: Oxford University Press.

Schmalensee, R., Joskow, P. L., Ellerman, A. D., Montero, J. P., \& Bailey, E. M. (1998). An interim evaluation of sulfur dioxide emissions trading. Journal of Economic Perspectives, 12(3), 53-68. doi: 10.1257/jep.12.3.53

Schmidt, J. P. (2019, March 4). For sale, by owner: The psychology of repugnant transactions. Retrieved from https://www.npr.org/2019/02/27/698563807/for-sale-by -owner-the-psychology-of-repugnant-transactions

The Sexual Offences Act. (2003). Retrieved from http://www.legislation.gov.uk/ ukpga/2003/42/section/52 (Accessed: 2019-01-07) 
Slovic, P. (1987). Perception of risk. Science, 236(4799), 280-285. doi: 10.1126/science .3563507

Soto, C. J., \& John, O. P. (2017). Short and extra-short forms of the Big Five Inventory 2: The BFI-2-S and BFI-2-XS. Journal of Research in Personality, 68, 69-81. doi: 10.1016/j.jrp.2017.02.004

Tetlock, P. E. (2003). Thinking the unthinkable: Sacred values and taboo cognitions. Trends in Cognitive Sciences, 7(7), 320-324. doi: 10.1016/S1364-6613(03)00135-9

Tetlock, P. E., Kristel, O. V., Elson, S. B., Green, M. C., \& Lerner, J. S. (2000). The psychology of the unthinkable: Taboo trade-offs, forbidden base rates, and heretical counterfactuals. Journal of Personality and Social Psychology, 78(5), 853-870. doi: $10.1037 / 0022-3514.78 .5 .853$

Tybur, J. M., Lieberman, D., \& Griskevicius, V. (2009). Microbes, mating, and morality: Individual differences in three functional domains of disgust. Journal of Personality and Social Psychology, 97(1), 103-122. doi: 10.1037/a0015474

Wallis, C. B., Samy, K. P., Roth, A. E., \& Rees, M. A. (2011). Kidney paired donation. Oxford University Press.

Wang, Y., \& Kosinski, M. (2018). Deep neural networks are more accurate than humans at detecting sexual orientation from facial images. Journal of Personality and Social Psychology, 114(2), 246-257. doi: 10.1037/pspa0000098

Wilkinson, M., \& Moore, A. (1997). Inducement in research. Bioethics, 11(5), 373-389. doi: $10.1111 / 1467-8519.00078$

Zelizer, V. A. R. (1979). Morals and markets: The development of life insurance in the United States. New York, NY: Columbia University Press. 